\title{
Microplastics Alter the Properties and Sinking Rates of Zooplankton Faecal Pellets
}

\author{
Matthew Cole, ${ }^{*}, \dagger$ Penelope K. Lindeque, ${ }^{\ddagger}$ Elaine Fileman, ${ }^{\ddagger}$ James Clark, ${ }^{\dagger \neq}$ Ceri Lewis, ${ }^{\dagger}$ \\ Claudia Halsband, ${ }^{\S}$ and Tamara S. Galloway ${ }^{\dagger}$ \\ ${ }^{\dagger}$ College of Life and Environmental Sciences, University of Exeter, Exeter EX4 4QD, United Kingdom \\ ‡Plymouth Marine Laboratory, Plymouth PL1 3DH, United Kingdom \\ ${ }^{\S}$ Akvaplan-niva AS, FRAM-High North Research Centre for Climate and the Environment, N-9296 Tromsø, Norway
}

\section{Supporting Information}

\begin{abstract}
Plastic debris is a widespread contaminant, prevalent in aquatic ecosystems across the globe. Zooplankton readily ingest microscopic plastic (microplastic, < $1 \mathrm{~mm}$ ), which are later egested within their faecal pellets. These pellets are a source of food for marine organisms, and contribute to the oceanic vertical flux of particulate organic matter as part of the biological pump. The effects of microplastics on faecal pellet properties are currently unknown. Here we test the hypotheses that (1) faecal pellets are a vector for transport of microplastics, (2) polystyrene microplastics can alter the properties and sinking rates of zooplankton egests and, (3) faecal pellets can facilitate the transfer of plastics to coprophagous biota. Following exposure to $20.6 \mu \mathrm{m}$ polystyrene microplastics $\left(1000\right.$ microplastics $\left.\mathrm{mL}^{-1}\right)$ and natural prey $\left(\sim 1650\right.$ algae $\left.\mathrm{mL}^{-1}\right)$ the copepod Calanus helgolandicus egested faecal pellets with significantly $(P<0.001)$ reduced densities, a 2.25 -fold reduction in sinking rates, and a higher propensity for fragmentation. We further show that microplastics, encapsulated within egests of the copepod Centropages typicus, could be transferred to C. helgolandicus via coprophagy. Our results support the proposal that sinking faecal matter represents a mechanism by which floating plastics can be vertically transported away from surface waters.

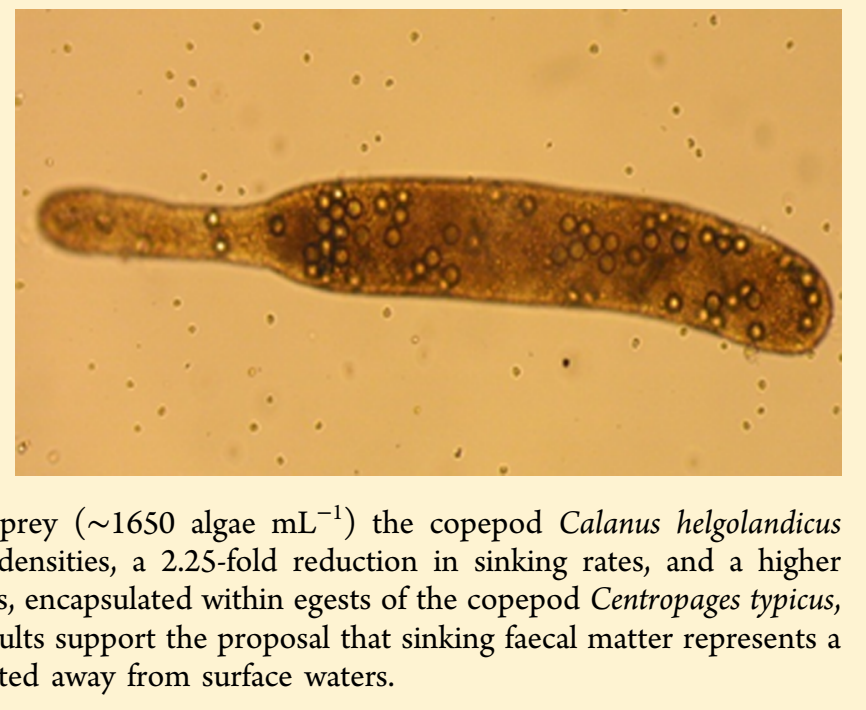

\section{INTRODUCTION}

Plastic debris is a pervasive anthropogenic contaminant, identified in marine ecosystems across the globe. ${ }^{1,2}$ In recent years, there has been growing concern that microscopic plastic (microplastic, $<1 \mathrm{~mm}$ diameter) debris could pose a threat to aquatic life, marine ecosystems, and human health. ${ }^{3-5}$ Microplastics include consumer items manufactured to be of a microscopic size (e.g., exfoliates in personal care products), ${ }^{6}$ or derive from the biological-, photo-, and/or mechanical degradation and subsequent fragmentation of larger plastic. ${ }^{7}$ Marine plastic debris stems from both terrestrial and maritime sources, ${ }^{8}$ and owing to its environmental persistence and buoyancy can be transported vast distances upon oceanic currents, affecting remote ecosystems including Arctic waters, deep-sea habitats, and midoceanic gyres. ${ }^{9-12}$ Recently Eriksen et al. estimated there are over 5 trillion microplastics floating in the ocean. ${ }^{2}$ In the North Pacific subtropical gyre the mass of neustonic plastic can exceed that of plankton 6-fold, ${ }^{13}$ and in Geoje Bay (Korea) waterborne concentrations of plastic can reach over 15500 particles $\mathrm{m}^{-3}$. $^{14}$

It is anticipated that interactions between plastics and biota will be most prevalent in productive coastal surface waters, in areas where low-density plastics, including polyethylene, polypropylene, and polystyrene, accumulate and overlap with the habitats of many pelagic animals. ${ }^{9,15}$ Consumption of plastic debris by marine organisms is commonplace, ${ }^{4}$ with studies identifying microplastics in the intestinal tracts of $25-28 \%$ of fish and $33 \%$ of shellfish sold at markets in the U.S. and Indonesia, ${ }^{16} 83 \%$ of the crustacea Nephrops norvegicus sampled from the Clyde Sea (U.K.), and approximately $3 \%$ of the copepod Neocalanus cristatus and 6\% of the euphausid Euphasia pacifica sampled in the NE Pacific. ${ }^{17}$ Laboratory-based, toxicological studies have identified that microplastic ingestion can lead to adverse health effects in a number of marine organisms, including: heightened immunological response in mussels; ${ }^{18}$ a reduction in the energetic reserves and bioturbation activity of polychaete worms; ${ }^{19}$ hepatic toxicity in fish; ${ }^{20}$ and reduced feeding, fecundity, and survival in marine copepods. ${ }^{21,22}$ Conversely, a number of studies have suggested that some larval organisms with more simplistic intestinal tracts, including oyster larvae ${ }^{23}$ and sea urchin larvae, ${ }^{24}$ demonstrate

Received: December 1, 2015

Revised: February 8, 2016

Accepted: February 11, 2016

Published: February 23, 2016 

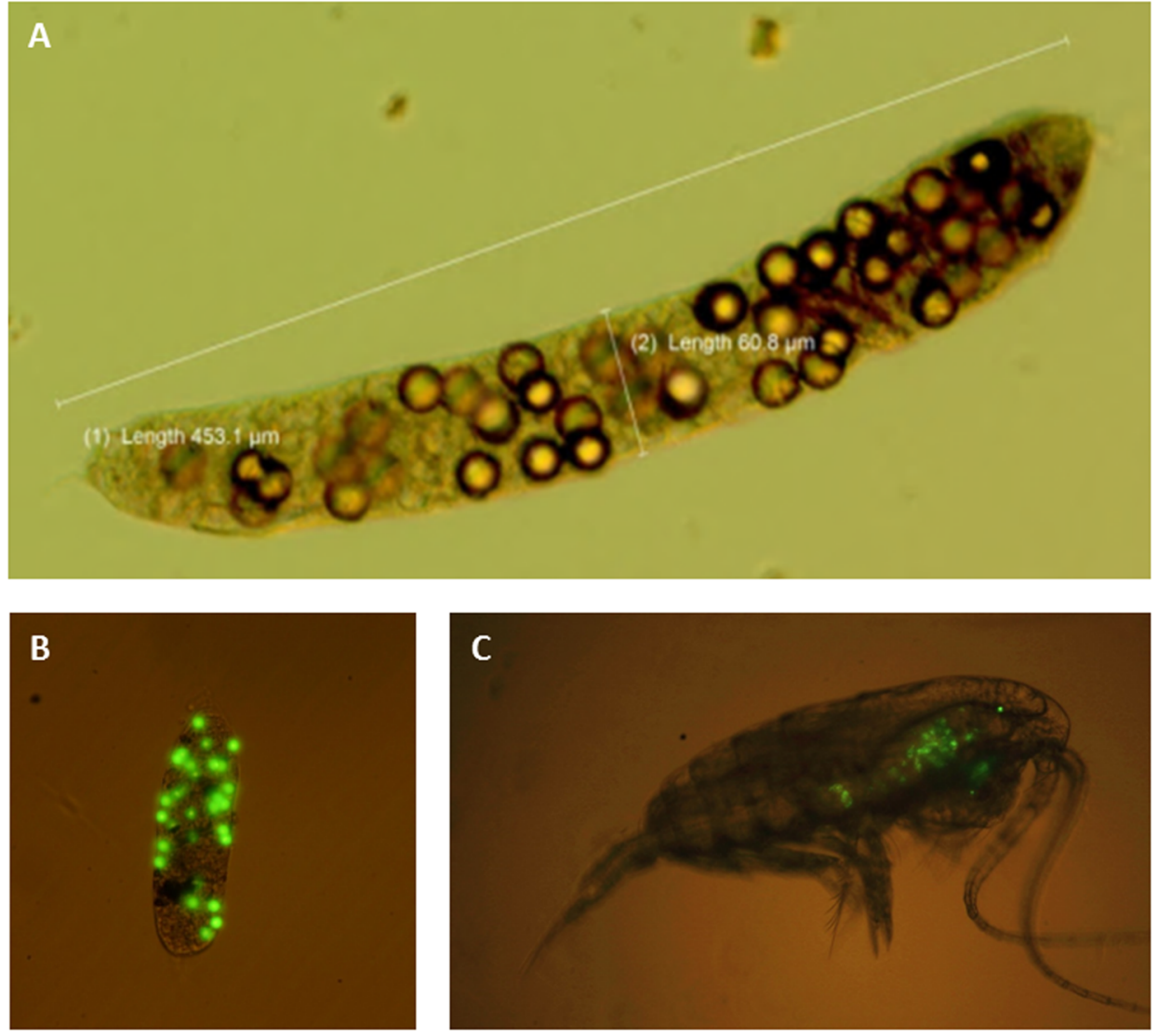

Figure 1. Microplastics encapsulated within faecal pellets can be consumed by coprophagous organisms. (A) A faecal pellet egested by the copepod C. helgolandicus, containing $20 \mu \mathrm{m}$ polystyrene microplastics, as measured using CellSens software (Olympus). (B) A faecal pellet egested by the copepod C. typicus, containing $7 \mu \mathrm{m}$ fluorescent polystyrene microplastics. (C) C. helgolandicus with $7 \mu \mathrm{m}$ fluorescent polystyrene beads in their midgut following uptake of a microplastic laden faecal pellet.

limited impact (i.e., feeding, growth and survival) from ingesting laboratory grade microplastics.

Copepods are an ecologically important group of heterotrophic zooplankton, ubiquitous within marine waters across the globe and one of the most abundant metazoans on the planet. ${ }^{25}$ In aquatic ecosystems, copepods form a key energetic link between primary producers and higher trophic organisms, and play an important (albeit variable) role in marine nutrient cycling through consuming and subsequently repackaging particulate organic matter (POM; e.g. plankton, detritus) into dense faecal pellets with high sinking velocities. ${ }^{26,27}$ The vertical flux of these pellets is integral to the biological pump, facilitating the transport of carbon, nutrients and POM to deeper waters and the benthos, thereby providing food for sediment-dwelling biota and promoting the oceanic storage of atmospherically derived carbon. ${ }^{28-30}$ It has been postulated that the incorporation of microplastics into faecal pellets may represent a mechanism by which floating plastics are transported away from surface waters. ${ }^{1,15}$ Recent laboratory studies have demonstrated that microplastics are readily consumed by copepods and that these microplastics are later egested along with waste organic matter in faecal pellets. ${ }^{21,31}$ However, it is currently unclear whether the presence of microplastics in copepod faecal pellets can affect their form, sinking rates, or fate, and whether this might have a localized impact on biogeochemical fluxes in regions of high contamination.

Here we investigate the consequences of microplastic egestion by copepods and test the hypothesis that incorpo- ration of polystyrene microplastics will reduce the density and sinking rates of their faecal pellets. We further test the hypothesis that consumption of faecal pellets (coprophagy) represents a pathway for indirect microplastic uptake by other marine organisms. Our study focuses on two marine copepods, common to the northeast Atlantic: Calanus helgolandicus and Centropages typicus. We discuss our findings in relation to the impact microplastics might have on the fate of faecal pellets in the environment.

\section{MATERIALS AND METHODS}

Copepods. Zooplankton were sampled from station L4 $\left(50^{\circ} 15^{\prime} \mathrm{N}, 04^{\circ} 13^{\prime} \mathrm{W}\right)$ and Plymouth Sound $\left(50^{\circ} 20^{\prime} \mathrm{N}\right.$, $\left.04^{\circ} 08^{\prime} \mathrm{W}\right)$, in the western English Channel, throughout April 2013 and October 2014. Specimens were collected via vertical haul and horizontal tow (WP2 nets), and then transported in insulated containers to Plymouth Marine Laboratory (PML) within $2 \mathrm{~h}$ of sampling. Adult C. helgolandicus and C. typicus were identified under a dissecting microscope and then transferred to $1 \mathrm{~L}$ of lightly aerated, filtered seawater (FSW; $0.22 \mu \mathrm{m}$ Millipore) for a minimum of $2 \mathrm{~h}$ to allow for gutdepuration.

Natural Prey. Concurrent with zooplankton collection in the western English Channel, we collected seawater containing natural assemblages of phytoplankton and organic matter. The seawater was screened through a $100 \mu \mathrm{m}$ mesh to remove mesozooplankton, stored in a $2 \mathrm{~L}$ carboy and maintained at ambient SST for $24 \mathrm{~h}$ prior to experimental use. The water 
predominantly contained phyto-flagellates, diatoms, including the centric genus Thalassiosira spp., and the coccolithophore Emiliania huxleyi.

Cultured Prey. The unicellular haptophyte Isochrysis galbana (CSAR Swansea) was cultured using F/2 media, at $20{ }^{\circ} \mathrm{C}$ in $16: 8$ light/dark conditions at the University of Exeter.

Microplastics. We used $20.6 \mu \mathrm{m}$ polystyrene (PS; Fluka Analytical: 74491) and $7.3 \mu \mathrm{m}$ fluorescent PS (Spherotech: PP6010) beads as representative microplastics. PS (density; $1.05 \mathrm{~g} \mathrm{~cm}^{-3}$ ) is neutrally buoyant in seawater (density: $\sim 1.03 \mathrm{~g}$ $\mathrm{cm}^{-3}$ ), is one of the most commonly manufactured polymers worldwide, ${ }^{32}$ and has been identified in surface and subsurface marine samples across the globe. ${ }^{9}$ Here we used PS at a concentration of 1000 microplastics $\mathrm{mL}^{-1}$, with equivalent mass dose of 4.8 and $0.2 \mathrm{~g} \mathrm{~m}^{-3}$ for 20.6 and $7.3 \mu \mathrm{m}$ beads, respectively (Supporting Information, Table S1). While these concentrations are generally higher that those reported in open ocean studies, ${ }^{10,13,46-50}$ they are consistent with concentrations observed in regions of high contamination ${ }^{14}$ (Table S2).

Experimental Setup. Copepods were incubated in $2 \mathrm{~L}$ glass beakers, filled with either $1750 \mathrm{~mL}$ of screened natural seawater $\left(\sim 1650\right.$ cells $\left.\mathrm{mL}^{-1}\right)$ for $C$. helgolandicus exposures, or FSW with cultured prey $\left(\sim 10000\right.$ cells $\left.\mathrm{mL}^{-1}\right)$ for $C$. typicus experiments, with microplastics added for the plastic treatments. An egg-production chamber, designed to limit egg cannibalism and coprophagy by separating adult copepods from their eggs and faecal pellets, and an air-stone was added to each beaker.

Faecal Pellet Analysis. Five adult $C$. helgolandicus were introduced to each beaker ( $n=5$ beakers per treatment). Exposures to microplastics were conducted in the dark at ambient SST for $18.5 \mathrm{~h}$. Postexposure, the contents of each beaker were carefully poured through a $20 \mu \mathrm{m}$ mesh (suspended in FSW) to retain faecal pellets. Faecal pellets were examined under a dissecting microscope and the number of whole and fragmented pellets recorded. The length and diameter of a subsample of intact faecal pellets $(n>10$ per replicate) were measured using an ocular micrometer in conjunction with an inverted light microscope (Olympus IMT2; Figure 1A). Measurements were used to calculate the equivalent cylindrical volume of the selected faecal pellets. Following volumetric measurement, the sinking rates $\left(\mathrm{m} \mathrm{day}^{-1}\right)$ of the subsampled faecal pellets were assessed using established methods: ${ }^{33,34}$ pellets were individually transferred via micropipette to a $1 \mathrm{~L}$ glass measuring cylinder, filled with FSW, maintained at $15{ }^{\circ} \mathrm{C}$ within a controlled temperature laboratory. Low-energy lights and colored backing sheets were arranged to aid visualization of the faecal pellets. Pellets were allowed to sink for $100 \mathrm{~mm}$ to achieve a constant velocity and then their descent was timed over a $33 \mathrm{~mm}$ distance (i.e., between horizontal graticules on the measuring cylinder). The density of each faecal pellet was calculated using Stoke's Law, as modified for use with cylindrical shapes (i.e., faecal pellets) with low Reynolds numbers. ${ }^{35}$

Coprophagy. Ten adult $C$. typicus were added to $1 \mathrm{~L}$ exposure vessels $(n=8$ per treatment). Microplastic exposures were conducted in the dark at ambient SST for $24 \mathrm{~h}$. Postexposure, the contents of each vessel were carefully poured through a $40 \mu \mathrm{m}$ mesh to collect faecal pellets, and rinsed with FSW to remove the PS beads. Faecal pellets were visualized under a fluorescent microscope to confirm microplastic incorporation and to ascertain that no waterborne PS beads remained. Each set of faecal pellets was subsequently transferred to a $23 \mathrm{~mL}$ glass bottle $(n=8$ bottles per treatment), filled to the brim with filtered seawater. A single $C$. helgolandicus (a copepod which can display coprophagy) ${ }^{36}$ was added to each bottle, and the vessels then gently rotated on a plankton wheel $(<5 \mathrm{rpm})$ at SST for $2 \mathrm{~h}$. Postexposure, the contents of each bottle were fixed ( $4 \%$ formalin) and subsequently viewed under an inverted light microscope with fluorescence (Olympus IMT2) to identify whether C. helgolandicus had ingested the microplastic-laden faecal pellets.

Statistical Analysis. Data were tested for normality using the Shapiro-Wilk or Kolmogorov-Smirnov tests as appropriate. A student's $t$ test or Wilcoxon signed-rank test were used to compare between treatments where applicable. A linear model was constructed to determine the relationship between sinking rates and faecal pellet volume and density, and then correlation coefficient $\left(\mathrm{R}^{2}\right)$ and significance calculated using regression analysis. Significant difference was attributed where $P \leq 0.05$. Statistical analysis was conducted using $R$. Data presented as mean $\pm \mathrm{SE}$.

\section{RESULTS}

The marine copepods C. helgolandicus and C. typicus both readily ingested microplastics. Following passage through the gut, microplastics were encapsulated in faecal pellets and egested (Figure 1A,B). Faecal pellets, including those containing polystyrene microplastics, sank to the base of the exposure vessels.

Incorporation of microplastics altered the density and sinking velocity, but not the size of faecal pellets egested by $C$. helgolandicus (control: $1.13 \pm 0.03 \times 10^{6} \mu \mathrm{m}^{3}$; plastic: $1.17 \pm$ $0.04 \times 10^{6} \mu \mathrm{m}^{3}$; $t$ test, $P=0.33$, Figure $2 \mathrm{~A}$ ). In the absence of
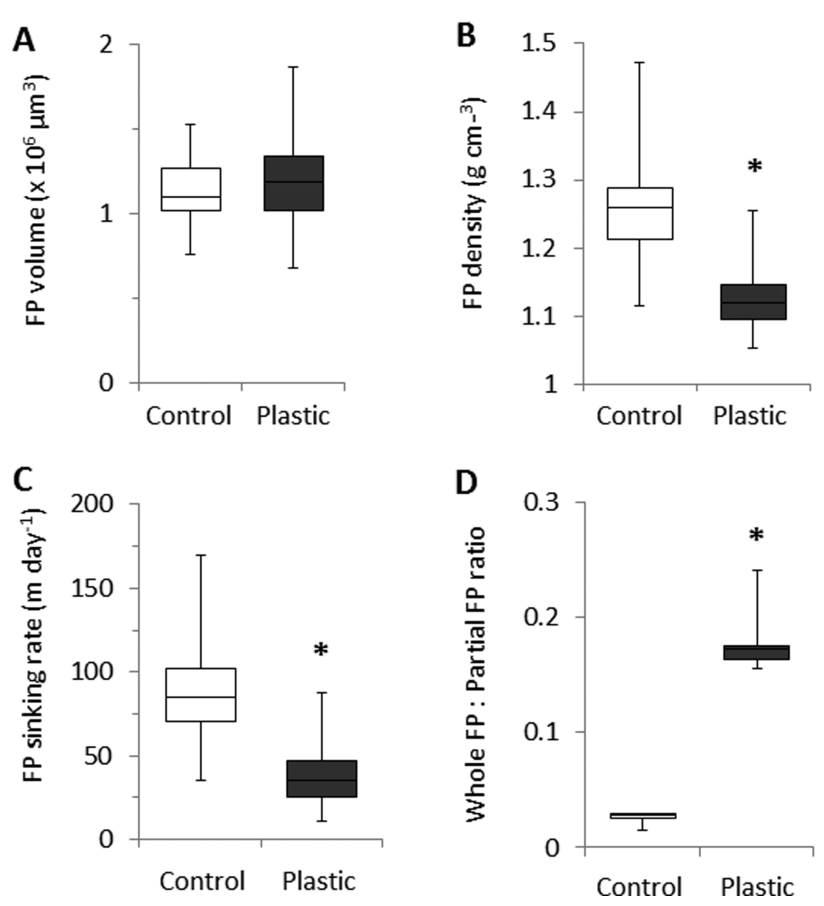

Figure 2. The impact of microplastics on faecal pellets egested by $C$. helgolandicus. (A) Comparative volume ( $t$ test, $\mathrm{df}=89, P=0.33$ ), (B) density ( $t$ test, $\mathrm{df}=85, P<0.01)$, and $(\mathrm{C})$ sinking rates $(t$ test, $\mathrm{df}=85$, $P<0.01$ ) of faecal pellets (FP) with and without microplastics. (D) Ratio between number of whole and partial FP following experimental conditions (Wilcox test, $n=5, P<0.01$ ). Treatments: control (white) and plastic (gray); asterisks indicate statistical significance $(P<0.01)$. 

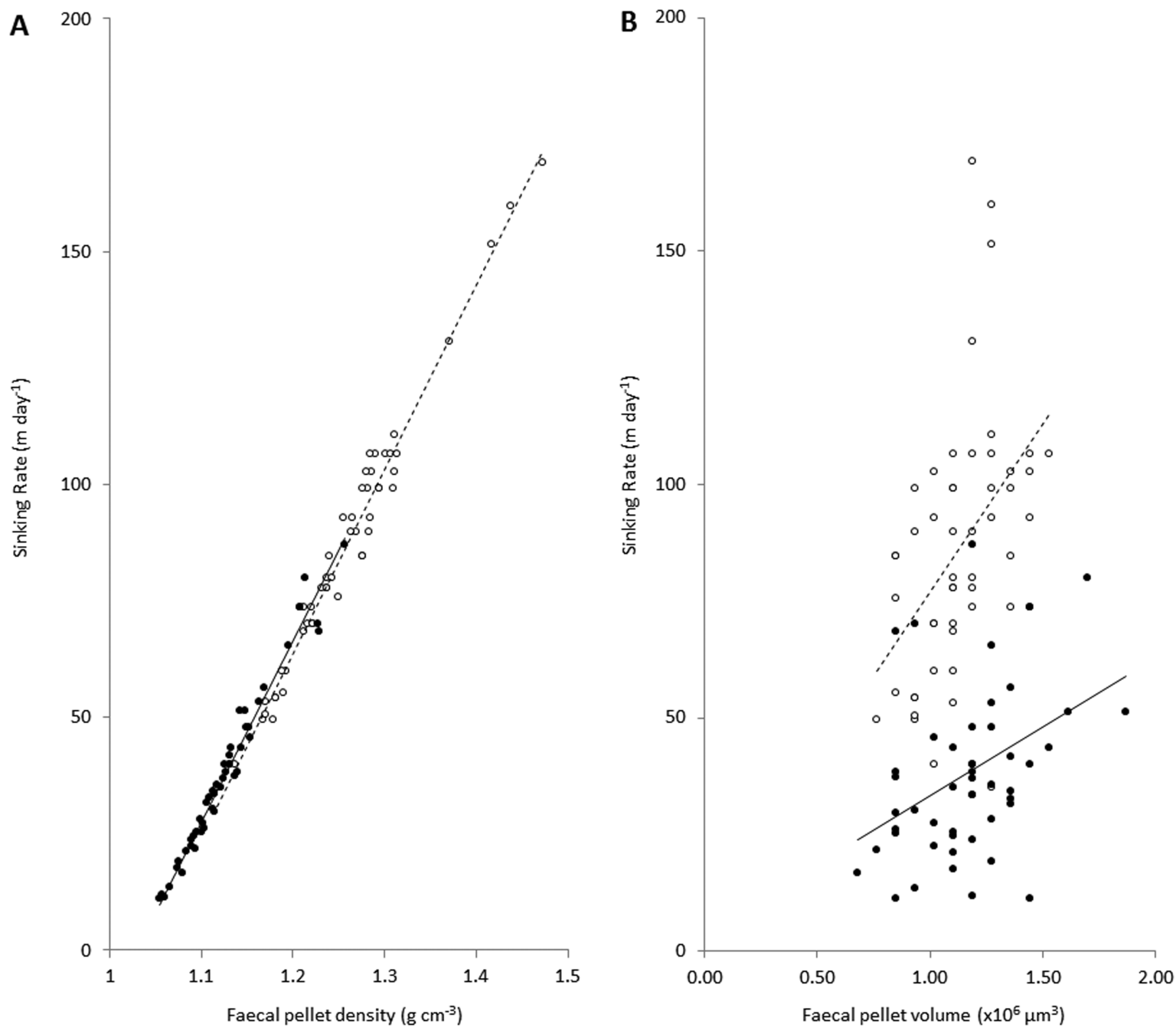

Figure 3. Relationship between faecal pellet sinking rates, volume and density. (A) Faecal pellet volume versus sinking rate (control: $\mathrm{R}^{2}=0.19, P<$ 0.01; plastic: $\mathrm{R}^{2}=0.14, P<0.01$ ). (B) Faecal pellet density versus sinking rate (control: $\mathrm{R}^{2}=0.98, P<0.01 ;$ plastic: $\mathrm{R}^{2}=0.97, P<0.01$ ). Treatments: control (white) and plastic (black); linear regression: control (dashed line) and plastic (solid line).

plastic, C. helgolandicus faecal pellets had an average density of $1.26 \pm 0.01 \mathrm{~g} \mathrm{~cm}^{-3}$ and settling velocity of $86.4 \pm 4.0 \mathrm{~m} \mathrm{day}^{-1}$. Faecal pellets containing polystyrene microplastics had significantly lower densities, averaging $1.13 \pm 0.01 \mathrm{~g} \mathrm{~cm}^{-3}(t$ test, df $=85, P<0.01$; Figure $2 \mathrm{~B})$ and significantly lower sinking velocities of $38.3 \pm 2.6 \mathrm{~m} \mathrm{day}^{-1}$ ( $t$ test, $\mathrm{df}=85, P<$ 0.01; Figure 2C).

Unsurprisingly, faecal pellet density had a very strong and significant influence on sinking rate (control: $\mathrm{R}^{2}=0.98, P<$ 0.01 ; plastic: $\mathrm{R}^{2}=0.97 ; P<0.01$; Figure $3 \mathrm{~A}$ ). With both treatments, faecal pellet sinking rates were significantly, albeit weakly, influenced by the pellet's volume (control: $\mathrm{R}^{2}=0.19, \mathrm{P}$ $<0.01$; plastic: $\mathrm{R}^{2}=0.14 ; P<0.01$; Figure $3 \mathrm{~B}$ ).

We observed no significant difference in the size of faecal pellets (Figure 2A) or egestion rate of copepods (control: 12.3 \pm 0.9 pellets copepod ${ }^{-1}$ day $^{-1}$; plastic: $13.0 \pm 0.8$ pellets copepod $^{-1}$ day $^{-1}$; $t$ test, $\left.P=0.64\right)$. However, we identified that a significantly greater number of faecal pellets containing microplastics became fragmented during the experiment (Wilcox test, $n=5, P<0.01$; Figure 2D).

Lastly, we demonstrated that microplastics encompassed within C. typicus faecal pellets (Figure 1B), could be transferred to a larger copepod (C. helgolandicus) via coprophagy (Figure
1C); the majority (75\%) of the C. helgolandicus contained fluorescent microplastics beads in their intestinal tract following a $2 \mathrm{~h}$ exposure with the faecal pellets. Following this exposure, we observed that a small number $(<20)$ of microplastic beads were free-floating within the surrounding water.

\section{DISCUSSION}

Our results demonstrate for the first time that microplastics can significantly alter the structural integrity, density, and sinking rates of faecal pellets egested by marine zooplankton. Our data also clearly demonstrate that microplastics can be indirectly ingested via consumption of faecal pellets, highlighting faecal pellets as a novel vector for microplastics.

We identified that copepods readily ingested and egested microplastics, which is consistent with previous findings. ${ }^{21,31}$ In the marine environment, zooplankton faecal pellets play an instrumental role in the biological pump, transporting POM, nutrients, carbon, and energy to deeper waters and the benthos. ${ }^{26,37}$ This vertical flux of faecal material can facilitate the movement of anthropogenic pollutants, including polycyclic aromatic hydrocarbons (PAHs) $)^{38}$ and hydrocarbon petroleum residues, ${ }^{39}$ to deeper waters. Our results confirm the hypothesis that copepod faecal pellets can also facilitate the vertical 
transport of microplastics. As a substantial proportion and vast range of marine organisms, including fish, cetaceans, turtles, seabirds, invertebrates, and zooplankton, are known to consume plastic debris, $3,12,17,40-42$ these results highlight sinking faecal matter as an important mechanism by which floating plastic litter could be removed from surface waters. The vertical redistribution of plastic litter has previously been attributed to mixing resulting from turbulence, storms, wind, and riverine inputs; ${ }^{10,43}$ the colonization of plastics by microbes and sessile organisms increasing their density; ${ }^{44,45}$ and, adhesion to marine aggregates. ${ }^{46}$ Collectively, these processes may explain why floating plastic debris, particularly particles $<1$ $\mathrm{mm}$ in size, are present in lower concentrations than conservative estimates predict. ${ }^{1,2}$

The incorporation of polystyrene microplastics significantly reduced the density of faecal pellets produced by $C$. helgolandicus, which was associated with a 2.25 -fold reduction in their sinking rate. If we were to extrapolate these rates to the average oceanic depth of $3682 \mathrm{~m},{ }^{47}$ then, hypothetically, faecal pellets containing the same proportion of polystyrene microplastics would take 53 days longer to reach the benthos than faecal pellets devoid of plastic. The in situ concentrations of microplastics in the targeted size range are to date poorly documented, and may be much more dilute than used in our experiments. We used $4.8 \mathrm{~g} \mathrm{~m}^{-3}$ of plastic, analogous to our approximations of the maximal mass of microplastic $(<2 \mathrm{~mm})$ identified in Geoje Bay (Korea); ${ }^{14}$ elsewhere maximal plastic concentrations, sampled with $200-500 \mu \mathrm{m}$ nets, are lower, ranging from 0.05 to $9.0 \mathrm{mg} \mathrm{m}^{-3}$ (Table S2). ${ }^{10,13,48-52}$ Nevertheless, the magnitude of change observed here is concerning, illustrating a novel potential impact of microplastic consumption in regions of high plastic contamination that we believe deserves more detailed investigation in the field. In oceanic conditions, faecal pellets and marine aggregates displaying reduced sinking speeds are more prone to consumption, fragmentation, and microbial degradation during their descent, resulting in their mineralization within the upper regions of the water column and therefore reduced POM export to deeper waters (Figure 4)..$^{27,28,30,53,54}$ It is widely recognized that prey composition can significantly affect a pellet's density: mineralizing phytoplankton (e.g., diatoms, coccolithophores), lithogenic material (e.g., dust, clay, sand), and anthropogenic particulates (e.g., drilling waste) can all have a ballasting effect on faecal pellets, increasing their sinking speeds. ${ }^{29,39}$ For example, in feeding on the dense, armored coccolithophore Emiliania huxleyi, C. helgolandicus produced faecal pellets with maximal sinking speeds of $>250 \mathrm{~m} \mathrm{~d}^{-1}$, far exceeding the "norm" for this copepod species. ${ }^{55}$ The influence of low-density microplastics on sinking particulates has been further demonstrated with marine aggregates. Adhesion of 2 $\mu \mathrm{m}$ PS microplastics decreased sinking speeds of marine snow, formed from the diatom Chaetoceros neogracile, from 473 to 165 $\mathrm{m} \mathrm{day}{ }^{-1}$, representing a 2.9 -fold decrease in their sinking velocity. ${ }^{46}$ However, changes to sinking rates were less evident in marine aggregates formed from the cryptophyte Rhodomonas salina, and mixtures of $C$. neogracile and $R$. salina. In the marine environment the sinking speeds of faecal pellets and aggregates will of course depend on a number of factors, including the quantity and type of plastic (e.g., polyethylene and polypropylene have densities lower than that of polystyrene) and organic material incorporated, and abiotic conditions such as the viscosity, temperature, salinity, homogeneity, and turbulence of the water column. ${ }^{27}$

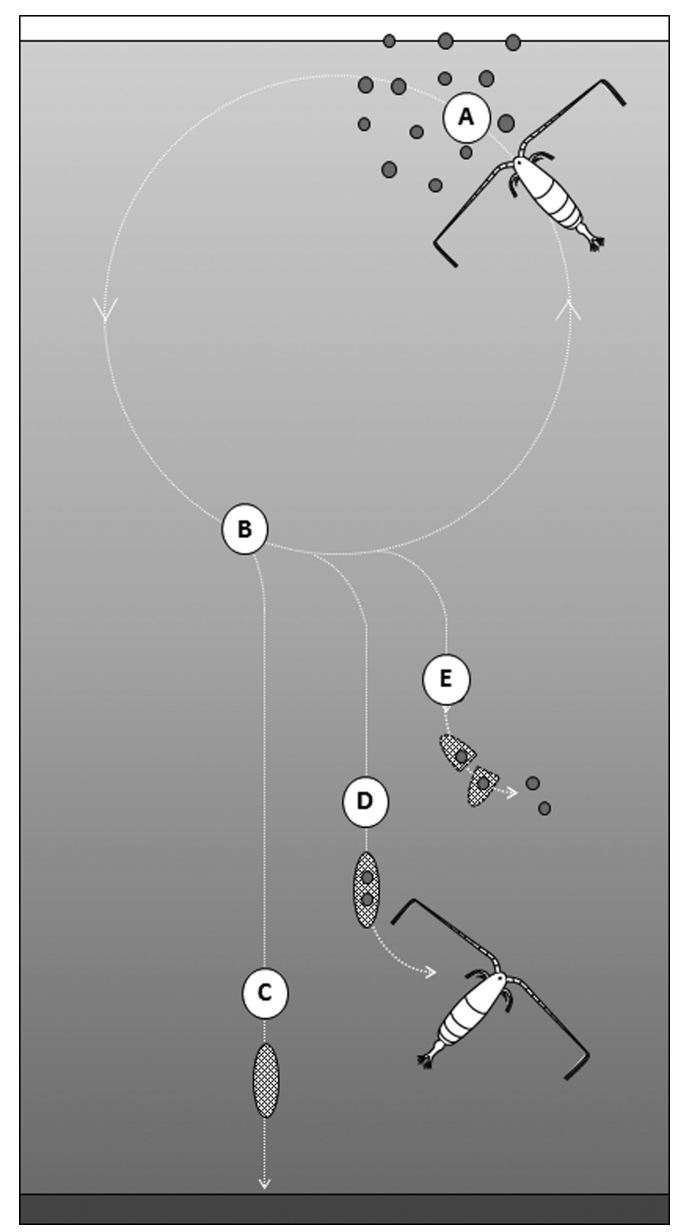

Figure 4. Conceptual schematic of microplastic transport via zooplankton in the water column. [A] Zooplankton ingest low-density microplastics in the euphotic zone; [B] zooplankton egest these microplastics within their faecal pellets (FP) in the upper water column; [C] normally FPs, full of densely packed organic material, will sink rapidly; and [D] FP containing low-density microplastics will sink significantly slower, making them susceptible to being eaten or [E] fragmented.

Faecal pellets consist of densely packed waste organic matter, enveloped within a peritrophic membrane produced in the midgut of the copepod. ${ }^{29}$ A greater number of broken (partial) pellets in the microplastic treatment would suggest a loss of structural integrity, likely owing to less organic material (relative to the pellet size) to bind the pellet together. In the marine environment, fragmentation of faecal pellets can result from consumption, physical damage, and turbidity. ${ }^{53,54}$ It can be hypothesized that these processes result in the creation of smaller pellet fragments, which, owing to the relationship between volume and sinking rate observed here (Figure 3A) and in the wider literature, will each have a lower sinking velocity than the whole pellet. ${ }^{27,47}$ Further, the smaller size of these fragments could increase their bioavailability to coprophagous biota, while larger surface area to volume ratios could result in faster rates of dissolution via microbial and protozooplankton action. ${ }^{44,5341,50}$ All of these pathways require further study and validation.

We identified that faecal pellets can act as a vector for the transfer of plastic from one organism to another. Previously laboratory studies have shown that microplastics can be trophically transferred through predator-prey interactions, 
from copepods to mysid shrimp, ${ }^{56}$ mussels to crabs, ${ }^{57,58}$ and fish to langoustine. ${ }^{59}$ The consumption of microplastics by marine biota can result in a range of adverse health effects including reduced feeding, the depletion of energetic reserves and heightened immune response $e^{18,19,31}$ and can facilitate the transfer of persistent organic pollutants and toxic additives. ${ }^{60}$ Faecal pellets are an important source of food for many marine animals, including (but not limited to) fish, polychaetes,

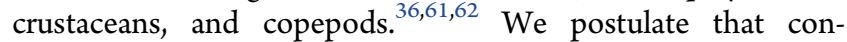
sumption of microplastic-laden pellets by coprophagous organisms would lead to further repackaging and recycling of microplastics within the marine trophic web and potential adverse health impacts to those organisms. Sinking organic matter is further subject to other biotic-interactions, including corprorhexy, whereby pellets are broken into fragments (with lower sinking velocities), and coprochaly, where the peritrophic membrane surrounding the pellet is disrupted releasing its contents into solution. ${ }^{53,5463}$ Previous studies have shown $C$. helgolandicus can readily capture faecal pellets, of which they consume $<37 \%$, while rejected pellets were damaged. ${ }^{60}$ This demonstration of coprophaly would explain why free-floating microplastics were observed in exposure media after $C$. helgolandicus were fed microplastic-laden faecal pellets. Although the number of waterborne particles were low $(<20)$, it is possible some of the plastics visualized in the guts of $C$. helgolandicus may have stemmed from the ingestion of these microplastics. Our study highlights that microplastics can affect the density, properties, and sinking rates of faecal pellets, raising the potential that faecal pellets could play a key role in the transport and trophic transfer of plastic in the ocean. In the marine environment a wide range of organisms, including zooplankton, have been identified as ingesting microplastics. In the NE Pacific, where maximal plastic concentrations range $0.05-0.30 \mathrm{mg} \mathrm{m}^{-3}, 49,51$ the zooplankton $N$. cristatus and E. pacifica have been found to consume microplastics (size range: $400-920 \mu \mathrm{m}$ ) at a rate of 1 particle per 34 copepods and 17 euphausiids, respectively. ${ }^{17}$ Although some animals can retain plastic debris in their intestinal tracts for several weeks, ${ }^{31,57}$ we postulate that the majority of microplastic debris will be egested. The relative contribution of zooplankton faecal pellets to the vertical flux of sinking organic matter is highly variable $(<1-100 \%)$, being mostly dependent on the community composition of phytoplankton and zooplankton in overlying waters. Our expectation is that plastics are most likely to be consumed, egested, and exert influence on faecal pellets in regions of high plastic contamination. ${ }^{15}$ Analysis of field collected faecal pellets and marine snows are now urgently required to assess the relative importance of these particulates as "plastic sinks" and determine the influence of plastic on the fate of zooplankton faecal pellets in oceanic conditions.

\section{ASSOCIATED CONTENT}

\section{S Supporting Information}

The Supporting Information is available free of charge on the ACS Publications website at DOI: 10.1021/acs.est.5b05905.

Tables detailing the mass of plastics used in the experiments and calculated mass of plastic identified in environmental samples from across the globe (PDF)

\section{AUTHOR INFORMATION}

\section{Corresponding Author}

*Telephone: +44 (0)1392 263436; E-mail: m.cole@exeter.ac. uk (M.C.).

\section{Funding}

This work was funded by a NERC standard grant (NE/ L007010).

\section{Notes}

The authors declare no competing financial interest.

\section{ACKNOWLEDGMENTS}

We thank the crew of Plymouth Quest for field sampling, Claire Widdicombe for phytoplankton analysis, and Angus Atkinson, Katsia Pabortsava, and Stephanie Wright for advice and expertise.

\section{REFERENCES}

(1) Cózar, A.; Echevarría, F.; González-Gordillo, J. I.; Irigoien, X.; Úbeda, B.; Hernández-León, S.; Palma, Á. T.; Navarro, S.; García-deLomas, J.; Ruiz, A. Plastic debris in the open ocean. Proc. Natl. Acad. Sci. U. S. A. 2014, 111 (28), 10239-10244.

(2) Eriksen, M.; Lebreton, L. C.; Carson, H. S.; Thiel, M.; Moore, C. J.; Borerro, J. C.; Galgani, F.; Ryan, P. G.; Reisser, J. Plastic Pollution in the World's Oceans: More than 5 Trillion Plastic Pieces Weighing over 250,000 Tons Afloat at Sea. PLoS One 2014, 9 (12), e111913.

(3) Cole, M.; Lindeque, P.; Halsband, C.; Galloway, T. S. Microplastics as contaminants in the marine environment: A review. Mar. Pollut. Bull. 2011, 62, 2588-2597.

(4) Gall, S.; Thompson, R. The impact of debris on marine life. Mar. Pollut. Bull. 2015, 92 (1), 170-179.

(5) Galloway, T. S. Micro-and nano-plastics and human health. In Marine Anthropogenic Litter; Springer: New York, 2015; pp 343-366.

(6) Napper, I. E.; Bakir, A.; Rowland, S. J.; Thompson, R. C. Characterisation, quantity and sorptive properties of microplastics extracted from cosmetics. Mar. Pollut. Bull. 2015, 99, 178-185.

(7) Andrady, A. L., Persistence of plastic litter in the oceans. In Marine Anthropogenic Litter; Springer: New York, 2015; pp 57-72.

(8) Cole, M.; Webb, H.; Lindeque, P.; Fileman, E.; Halsband, C.; Galloway, T. S. Isolation of microplastics in biota-rich samples and marine biota. Sci. Rep. 2014, 4.10.1038/srep04528

(9) Hidalgo-Ruz, V.; Gutow, L.; Thompson, R. C.; Thiel, M. Microplastics in the marine environment: a review of the methods used for identification and quantification. Environ. Sci. Technol. 2012, 46 (6), 3060-3075.

(10) Lattin, G. L.; Moore, C. J.; Zellers, A. F.; Moore, S. L.; Weisberg, S. B. A comparison of neustonic plastic and zooplankton at different depths near the southern California shore. Mar. Pollut. Bull. 2004, 49 (4), 291-294.

(11) Law, K. L.; Moret-Ferguson, S.; Maximenko, N. A.; Proskurowski, G.; Peacock, E. E.; Hafner, J.; Reddy, C. M. Plastic Accumulation in the North Atlantic Subtropical Gyre. Science 2010, $329,1185-1188$.

(12) Lusher, A. Microplastics in the marine environment: distribution, interactions and effects. In Marine Anthropogenic Litter; Springer: New York, 2015; pp 245-307.

(13) Moore, C. J.; Moore, S. L.; Leecaster, M. K.; Weisberg, S. B. A Comparison of Plastic and Plankton in the North Pacific Central Gyre. Mar. Pollut. Bull. 2001, 42 (12), 1297-1300.

(14) Kang, J.-H.; Kwon, O. Y.; Lee, K.-W.; Song, Y. K.; Shim, W. J. Marine neustonic microplastics around the southeastern coast of Korea. Mar. Pollut. Bull. 2015, 96 (1-2), 304-312.

(15) Clark, J. R.; Cole, M.; Lindeque, P.; Fileman, E.; Blackford, J.; Lewis, C.; Lenton, T. M.; Galloway, T. S. Marine plastic debris: a targeted plan for understanding and quantifying interactions with marine life. Front. Ecol. Environ., accepted. 
(16) Rochman, C. M.; Tahir, A.; Williams, S. L.; Baxa, D. V.; Lam, R.; Miller, J. T.; Teh, F.-C.; Werorilangi, S.; Teh, S. J. Anthropogenic debris in seafood: Plastic debris and fibers from textiles in fish and bivalves sold for human consumption. Sci. Rep. 2015, 5.1434010.1038/ srep 14340

(17) Desforges, J.-P. W.; Galbraith, M.; Ross, P. S. Ingestion of Microplastics by Zooplankton in the Northeast Pacific Ocean. Arch. Environ. Contam. Toxicol. 2015, 69 (4), 320-330.

(18) von Moos, N.; Burkhardt-Holm, P.; Köhler, A. Uptake and effects of microplastics on cells and tissue of the blue mussel Mytilus edulis L. after an experimental exposure. Environ. Sci. Technol. 2012, 46 (20), 11327-11335.

(19) Wright, S. L.; Rowe, D.; Thompson, R. C.; Galloway, T. S. Microplastic ingestion decreases energy reserves in marine worms. Curr. Biol. 2013, 23 (23), 1031-1033.

(20) Rochman, C. M.; Hoh, E.; Kurobe, T.; Teh, S. J. Ingested plastic transfers hazardous chemicals to fish and induces hepatic stress. Sci. Rep. 2013, 3.10.1038/srep03263

(21) Lee, K.-W.; Shim, W. J.; Kwon, O. Y.; Kang, J.-H. SizeDependent Effects of Micro Polystyrene Particles in the Marine Copepod Tigriopus japonicus. Environ. Sci. Technol. 2013, 47 (19), 11278-11283.

(22) Cole, M.; Lindeque, P.; Fileman, E.; Halsband, C.; Galloway, T. The impact of polystyrene microplastics on feeding, function and fecundity in the marine copepod Calanus helgolandicus. Environ. Sci. Technol. 2015, 49 (2), 1130-1137.

(23) Cole, M.; Galloway, T. Ingestion of nanoplastics and microplastics by Pacific oyster larvae. Environ. Sci. Technol. 2015, 49, 14625-14632.

(24) Kaposi, K. L.; Mos, B.; Kelaher, B.; Dworjanyn, S. A. Ingestion of microplastic has limited impact on a marine larva. Environ. Sci. Technol. 2013, 48 (3), 1638-1645.

(25) Mauchline, J. The Biology of Calanoid Copepods; Academic Press: London, 1998.

(26) Turner, J. T. Zooplankton fecal pellets, marine snow and sinking phytoplankton blooms. Aquat. Microb. Ecol. 2002, 27 (1), 57-102.

(27) Turner, J. T. Zooplankton fecal pellets, marine snow, phytodetritus and the ocean's biological pump. Prog. Oceanogr. 2015, $130,205-248$.

(28) Buesseler, K. O.; Lamborg, C. H.; Boyd, P. W.; Lam, P. J.; Trull, T. W.; Bidigare, R. R.; Bishop, J. K.; Casciotti, K. L.; Dehairs, F.; Elskens, M. Revisiting carbon flux through the ocean's twilight zone. Science 2007, 316 (5824), 567-570.

(29) Small, L.; Fowler, S.; Ünlü, M. Sinking rates of natural copepod fecal pellets. Mar. Biol. 1979, 51 (3), 233-241.

(30) Giering, S. L.; Sanders, R.; Lampitt, R. S.; Anderson, T. R.; Tamburini, C.; Boutrif, M.; Zubkov, M. V.; Marsay, C. M.; Henson, S. A.; Saw, K. Reconciliation of the carbon budget in the ocean/'s twilight zone. Nature 2014, 507 (7493), 480-483.

(31) Cole, M.; Lindeque, P.; Fileman, E.; Halsband, C.; Goodhead, R.; Moger, J.; Galloway, T. S. Microplastic ingestion by zooplankton. Environ. Sci. Technol. 2013, 12, 6646-6655.

(32) PlasticsEurope Plastics-the facts 2013. http://www. plasticseurope.org/ (01.03.14).

(33) Fowler, S. W.; Small, L. F. Sinking rates of euphausiid fecal pellets. Limnol. Oceanogr. 1972, 17 (2), 293-296.

(34) Smayda, T. J. Some measurements of the sinking rate of fecal pellets. Limnol. Oceanogr. 1969, 14, 621-625.

(35) Komar, P. D.; Morse, A. P.; Small, L. F.; Fowler, S. W. An analysis of sinking rates of natural copepod and euphausiid fecal pellets. Limnol. Oceanogr. 1981, 26 (1), 172-180.

(36) Paffenhöfer, G. A.; Strickland, J. D. H. A note on the feeding of Calanus helgolandicus on detritus. Mar. Biol. 1970, 5 (2), 97-99.

(37) Fowler, S. W.; Buat-Menard, P.; Yokoyama, Y.; Ballestra, S.; Holm, E.; Van Nguyen, H. Rapid removal of Chernobyl fallout from Mediterranean surface waters by biological activity. Nature 1987, 329, $56-58$.

(38) Prahl, F. G.; Carpenter, R. The role of zooplankton fecal pellets in the sedimentation of polycyclic aromatic hydrocarbons in Dabob
Bay, Washington. Geochim. Cosmochim. Acta 1979, 43 (12), 19591972.

(39) Sleeter, T. D.; Butler, J. N. Petroleum hydrocarbons in zooplankton faecal pellets from the Sargasso Sea. Mar. Pollut. Bull. 1982, 13 (2), 54-56.

(40) Wright, S. L.; Thompson, R. C.; Galloway, T. S. The physical impacts of microplastics on marine organisms: A review. Environ. Pollut. 2013, 178 (0), 483-492.

(41) Nelms, S. E.; Duncan, E. M.; Broderick, A. C.; Galloway, T. S.; Godfrey, M. H.; Hamann, M.; Lindeque, P. K.; Godley, B. J. Plastic and marine turtles: a review and call for research. ICES J. Mar. Sci. 2016, 73, 165-181.

(42) Boerger, C. M.; Lattin, G. L.; Moore, S. L.; Moore, C. J. Plastic ingestion by planktivorous fishes in the North Pacific Central Gyre. Mar. Pollut. Bull. 2010, 60 (12), 2275-2278.

(43) Browne, M. A.; Galloway, T. S.; Thompson, R. C. Spatial Patterns of Plastic Debris along Estuarine Shorelines. Environ. Sci. Technol. 2010, 44 (9), 3404-3409.

(44) Harrison, J. P.; Schratzberger, M.; Sapp, M.; Osborn, A. M. Rapid bacterial colonization of low-density polyethylene microplastics in coastal sediment microcosms. BMC Microbiol. 2014, 14 (1), 232.

(45) Zettler, E. R.; Mincer, T. J.; Amaral-Zettler, L. A. Life in the 'Plastisphere': Microbial communities on plastic marine debris. Environ. Sci. Technol. 2013, 47 (13), 7137-7146.

(46) Long, M.; Moriceau, B.; Gallinari, M.; Lambert, C.; Huvet, A.; Raffray, J.; Soudant, P. Interactions between microplastics and phytoplankton aggregates: Impact on their respective fates. Mar. Chem. 2015, 175, 39-46.

(47) Charette, M. A.; Smith, W. H. The volume of Earth's ocean. Oceanogr. 2010, 23, 112-114.

(48) Moore, C. J.; Moore, S. L.; Weisberg, S. B.; Lattin, G. L.; Zellers, A. F. A comparison of neustonic plastic and zooplankton abundance in southern California's coastal waters. Mar. Pollut. Bull. 2002, 44 (10), 1035-1038.

(49) Doyle, M. J.; Watson, W.; Bowlin, N. M.; Sheavly, S. B. Plastic particles in coastal pelagic ecosystems of the Northeast Pacific ocean. Mar. Environ. Res. 2011, 71 (1), 41-52.

(50) Collignon, A.; Hecq, J.-H.; Galgani, F.; Voisin, P.; Collard, F.; Goffart, A. Neustonic microplastic and zooplankton in the North Western Mediterranean Sea. Mar. Pollut. Bull. 2012, 64 (4), 861-864.

(51) Goldstein, M. C.; Goodwin, D. S. Gooseneck barnacles (Lepas spp.) ingest microplastic debris in the North Pacific Subtropical Gyre. PeerJ 2013, 1, e184.

(52) Reisser, J.; Slat, B.; Noble, K.; du Plessis, K.; Epp, M.; Proietti, M.; de Sonneville, J.; Becker, T.; Pattiaratchi, C. The vertical distribution of buoyant plastics at sea: an observational study in the North Atlantic Gyre. Biogeosciences 2015, 12 (4), 1249-1256.

(53) Iversen, M.; Poulsen, L. K. Coprohexy, coprophagy, and coprochaly in the copepods Calanus helgolandicus, Pseudocalanus elongatus, and Oithona similis. Mar. Ecol.: Prog. Ser. 2007, 350, 79-89.

(54) Lampitt, R.; Noji, T.; Von Bodungen, B. What happens to zooplankton faecal pellets? Implications for material flux. Mar. Biol. 1990, 104 (1), 15-23.

(55) Harris, R. Zooplankton grazing on the coccolithophore Emiliania huxleyi and its role in inorganic carbon flux. Mar. Biol. 1994, 119 (3), 431-439.

(56) Setälä, O.; Fleming-Lehtinen, V.; Lehtiniemi, M. Ingestion and transfer of microplastics in the planktonic food web. Environ. Pollut. 2014, 185, 77-83.

(57) Watts, A. J.; Lewis, C.; Goodhead, R. M.; Beckett, S. J.; Moger, J.; Tyler, C. R.; Galloway, T. S. Uptake and retention of microplastics by the shore crab Carcinus maenas. Environ. Sci. Technol. 2014, 48 (15), 8823-8830.

(58) Farrell, P.; Nelson, K. Trophic level transfer of microplastic: Mytilus edulis (L.) to Carcinus maenas (L.). Environ. Pollut. 2013, 177, $1-3$.

(59) Murray, F.; Cowie, P. R. Plastic contamination in the decapod crustacean Nephrops norvegicus (Linnaeus, 1758). Mar. Pollut. Bull. 2011, 62 (6), 1207-1217. 
(60) Rochman, C. M., The complex mixture, fate and toxicity of chemicals associated with plastic debris in the marine environment. In Marine Anthropogenic Litter; Springer: New York, 2015; pp 117-140.

(61) Johannes, R.; Satomi, M. Composition and nutritive value of fecal pellets of a marine crustacean. Limnol. Oceanogr. 1966, 11 (2), 191-197.

(62) Frankenberg, D.; Smith, K. Coprophagy in marine animals. Limnol. Oceanogr. 1967, 12, 443-450.

(63) Noji, T. T.; Estep, K. W.; Macintyre, F.; Norrbin, F. Image analysis of faecal material grazed upon by three species of copepods: evidence for coprorhexy, coprophagy and coprochaly. J. Mar. Biol. Assoc. U. K. 1991, 71 (02), 465-480. 